\title{
Static contact angle versus volume of distilled water drop on micro patterned surfaces
}

\author{
Kseniya Batichsheva ${ }^{1, *}$, Dmitriy Feoktistov ${ }^{2}$, Vladimir Ovchinikov ${ }^{2}$, and Sergey Misyura ${ }^{2}$ \\ ${ }^{1}$ National Research Tomsk Polytechnic University, 634050 Tomsk, Russia \\ ${ }^{2}$ Kutateladze Institute of Thermophysics, 630090 Novosibirsk, Russia
}

\begin{abstract}
Static contact angle was determined experimentally in the condition of wetting of polished and laser patterned surfaces of stainless steel substrates by distilled water drops with different volumes. In contrast with polished surface, the contact angle was found to depend on drop volume on micro patterned surfaces. In addition, the enhancement of both hydrophilic and hydrophobic properties was observed on laser patterned surfaces.
\end{abstract}

\section{Introduction}

Nowadays there is a search of ways to create surfaces with controlled wetting. Studies in this field [1-5] are motivated by developing the scientific bases of creation of self-cleaning, anti-microbial, anti-corrosion, waterproof materials. It is known [6-8] that many factors affect the intermolecular interaction of condensed liquid and solid phases. The main factors are the chemical composition of the liquid and the surface, and the roughness. To create special micro or nanostructures modifying wetting properties, the following methods are used: sublimation, templating methods, chemical deposition of structures from the gas phase, lithography. All of them require significant financial costs; their technical implementation takes much time. The laser light is promising as a method of surface treatment to create the necessary wetting properties. It is relatively low-cost and technologically simple. However, the scientific bases of using laser are not developed at a level to create the metal surfaces with hydrophobic or hydrophilic properties [9-23].

The purpose of this work is to determine experimentally the dependence of the static contact angle $(\theta)$ on the distilled water drop volume $(\mathrm{V})$ on the treated surfaces by the laser radiation.

\section{Experimental procedure}

Experimental studies were carried out on the setup; the principle of its operation is shown in [24]. We used eleven laser patterned and one polished surfaces made of stainless steel. Technical characteristics used for each surface in "MiniMarker 2 M 20" laser system are listed in Table 1.

*Corresponding author: bka1801@mail.ru 
The drop was placed on the surface by the precision dispenser. The following drop

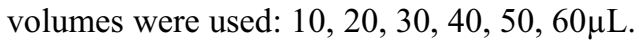

Table 1. Technical characteristics of "MiniMarker 2 M 20" laser system used during surface treatment.

\begin{tabular}{|c|c|c|c|c|c|c|c|c|c|c|c|}
\hline $\begin{array}{c}\text { No of samples } \\
\text { made of stainless } \\
\text { steel }\end{array}$ & $\mathbf{1}$ & $\mathbf{2}$ & $\mathbf{3}$ & $\mathbf{4}$ & $\mathbf{5}$ & $\mathbf{6}$ & $\mathbf{7}$ & $\mathbf{8}$ & $\mathbf{9}$ & $\mathbf{1 0}$ & $\mathbf{1 1}$ \\
\hline $\begin{array}{c}\text { Frequency of laser } \\
\text { beam, Hz }\end{array}$ & 99 & 99 & 99 & 50 & 50 & 20 & 20 & 99 & 99 & 99 & 99 \\
\hline $\begin{array}{c}\text { Traverse speed of } \\
\text { laser beam, } \\
10^{-3} \mathrm{~m} / \mathrm{s}\end{array}$ & 200 & 400 & 800 & 800 & 400 & 200 & 800 & 800 & 800 & 800 & 800 \\
\hline $\begin{array}{c}\text { Power of laser } \\
\text { radiation, Wt }\end{array}$ & 20 & 20 & 20 & 20 & 20 & 20 & 20 & 10 & 14 & 16 & 18 \\
\hline
\end{tabular}

The average arithmetic roughness $(\mathrm{Ra})$ was defined by using "HOMMEL TESTER T1000" profilometer.

\section{Results and discussion}

Systematic component of the error was neglected. Parasitic errors were rejecting during processing stage. Each experiment was repeated at least five times. All experimental results at fixed parameters were average. The relative measurement error did not exceed 5\%.

According to the experimental results, dependences of static contact angle on liquid volume were obtained (Fig.1).

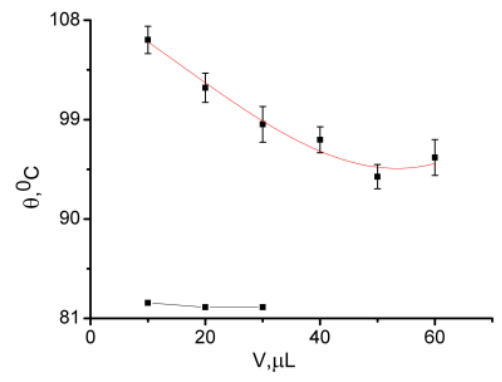

a

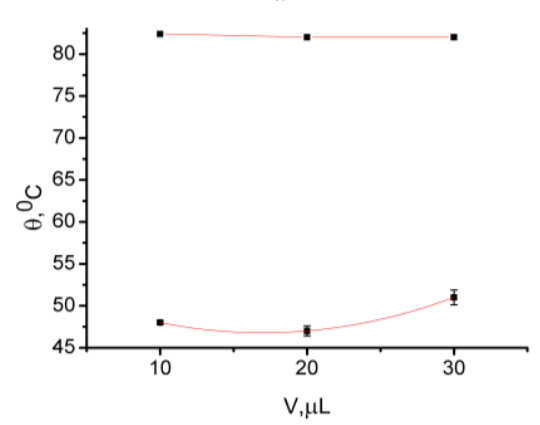

C

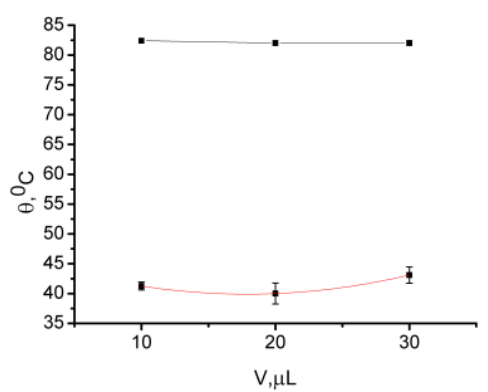

b

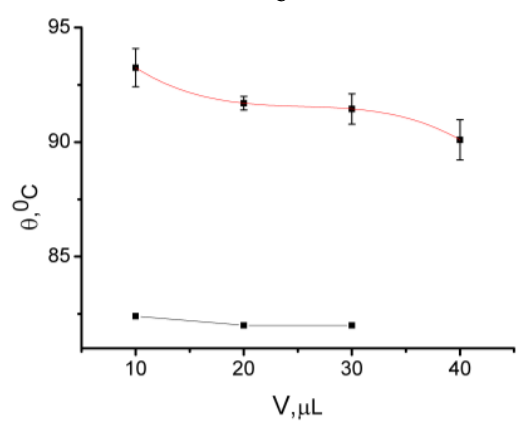

d 

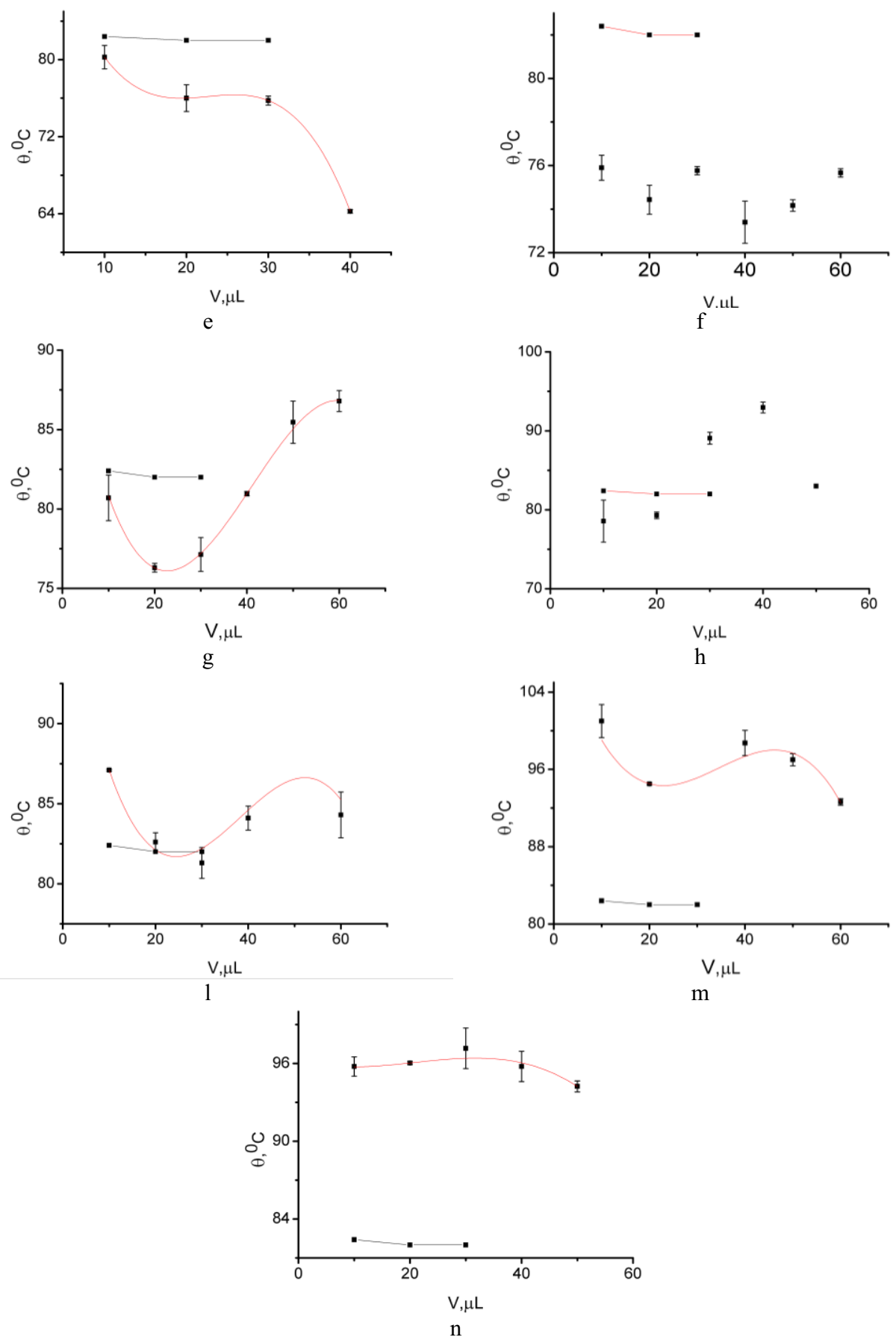

Fig. 1. Dependences of static contact angle on distilled water drop on stainless steel surfaces with numbers: a) 1 ; b) 2 ; c) 3 ; d) 4; e) 5; f) 6 ; g) 7; h) 8 ; 1) 9; m) 10; n) 11. Contact angle on: 1 - polished surface; 2 - patterned surface.

The static contact angle is found not to depend on the volume on stainless steel polished surface $(\mathrm{Ra}=0.079 \mu \mathrm{m})$. However, on laser patterned surfaces the static contact angle 
depends on the liquid volume and microstructure (Fig.3). The change of the contact angle $\theta$ can be explained by the following way. The behaviour of drop on the surface is known to be described by to models, Wenzel and Cassie-Baxter states. The first model characterizes heterogeneous wetting when the liquid does not penetrate into the micro cavities on the surface. The second one is homogeneous; the liquid penetrates into the micro cavities. In the Cassie-Baxter state (1) the proportion of projection of wetting area on substrate surface changes at increasing liquid volume:

$$
\cos \theta=f\left(\cos \theta_{0}+1\right)-1
$$

Decrease in this proportion leads to increase in static contact angle. It can be concluded that the portion of curves (Fig.3), where $\theta$ decreases with increase in volume, correspond to the Cassie-Baxter state. A further increase in liquid volume results in complete filling of the cavities on the surface. There is a transition from heterogeneous to homogeneous wetting mode. It can be assumed that the portion, where $\theta$ changes sharply, corresponds to the transition from the state of Cassie-Baxter to the Wenzel state.

It is found that the static contact angle increased on surfaces No 1, 4, 9, 10, 11 (the hydrophobic properties improved). However, $\theta$ decreased on the surfaces No 2, 3, 5, 6 (the hydrophilic properties improved). The curves of static contact angle on surfaces No 7, 8 have a sinusoid nature.

\section{Conclusion}

The influence of the volume of distilled water on the value of the static contact angle of a drop placed on laser patterned surface made of stainless steel was studied. The possibility of controlling the wetting by laser treatment of surfaces was approved. The micro asperities and cavities are found not to impact the static contact angle on relatively smooth surfaces $(\mathrm{Ra}=0.079 \mu \mathrm{m})$. The static contact angle on patterned surfaces compared to polished depends on the liquid volume. Change of laser radiation power, impulse frequency and traverse speed of laser beam allows to improve hydrophilic, as well as hydrophobic properties.

This work was carried out at the Kutateladze Institute of Thermophysics SB RAS and financially supported by the Russian Science Foundation (project number 15-19-10025).

\section{References}

1. O.A. Kabov, D.V. Zaitsev, Multiphase Sci. Technol. 2, 249 (2009)

2. D.V. Zaitsev, O.A. Kabov, V.V. Cheverda, N.S. Bufetov, High. Temp. 42, 450 (2004)

3. V.E. Nakoryakov, S.Y. Misyura, S.L. Elistratov, J. Eng. Thermophys. 22, 1 (2013)

4. S.Y. Misyura, V.E. Nakoryakov, S.L. Elistratov, Int. J. Energy Technol. 4, 1 (2012)

5. G.V. Kuznetsov, A.V. Zakharevich, N.S. Bel'kov, Chem. Pet. Eng. 50, 424 (2014)

6. A.V. Zakharevich, N.S. Bel'kov, EPJ Web Conf. 76, 01081 (2014)

7. D.O. Glushkov, G.V. Kuznetsov, P.A. Strizhak, Therm. Sci. 19, 1541 (2015)

8. D.O. Glushkov, G.V. Kuznetsov, P.A. Strizhak, R.S. Volkov, Therm. Sci. 20, 131 (2016)

9. V.P. Lebedev V.V. Lemanov, S.Y. Misyura, V.I. Terekhov, Fluid Dyn. 28, 624 (1993)

10. S.Y. Misyura, Exp. Therm Fluid Sci.75, 43 (2016)

11. D.O. Glushkov, J.-C. Legros, P.A. Strizhak, A.V. Zakharevich, Fuel. 175, 105 (2016)

12. V.I. Maksimov, T.A. Nagornova, I.A. Shestakov, EPJ Web Conf. 82, 01048 (2015)

13. D.V. Zaitsev, D.P. Kirichenko, O.A. Kabov, Tech. Phys. Lett. 41, 551 (2015) 
14. A. Sivkov, A. Ivashutenko, Y. Shanenkova, I. Shanenkov, Adv. Powder Technol. 27, $1506(2016)$

15. A. Sivkov, A., I. Shanenkov, A. Pak, D. Gerasimov, Y. Shanenkova, Surf. Coat. Technol. 291, 1 (2016)

16. G.V. Kuznetsov, D.V. Feoktistov, E.G. Orlova, Thermophys. Aeromech. 23, 17 (2016)

17. Y.V. Lyulin, D.V. Feoktistov, I.A. Afanas'ev, E.S. Chachilo, O.V. Kabov, G.V. Kuznetsov, Tech. Phys. Lett. 41, 665 (2015)

18. D.V. Feoktistov, E.G. Orlova, A.G. Islamova, Eur. Phys. J. Conf. 110, 98 (2016)

19. K.O. Ponomarev, E.G. Orlova, D.V. Feoktistov, EPJ Web Conf. 110, 01060 (2016)

20. E.G. Orlova, G.V. Kuznetsov, D.V. Feoktistov, EPJ Web Conf. 76, 01039 (2014)

21. O.V. Vysokomornaya, G.V. Kuznetsov, P.A. Strizhak, Russ. J. Phys. Chem. B. 5, 668 (2011)

22. G.V. Kuznetsov, M.A. Sheremet, J. Comput. Thermal Sci. Internat. 1, 341 (2009)

23. R.S. Volkov, G.V. Kuznetsov, P.A. Strizhak, Int. J. Heat Mass Tran. 85, 1 (2015)

24. G.V. Kuznetsov, D.V. Feoktistov, E.G. Orlova, Thermophys. Aeromech. 23, 17 (2016) 